\title{
Consenso do Simpósio Promovido pela Associação Gaúcha de Odontopediatria sobre Riscos e Benefícios de Dentifrícios Fluoretados na Primeira Infância
}

\author{
Consensus of the Symposium Promoted by Associação Gaúcha de Odontopediatria about Risks and \\ Benefits of Fluoride Dentifrices in Primary Childhood
}

\section{Fernando Neves Hugo ${ }^{1}$, Cassiano Kuchenbecker Rosing ${ }^{2}$, Fernando Borba de Araujo ${ }^{3}$}

\begin{abstract}
This Consensus reports the conclusions from the Symposium promoted by the Associação Gaúcha de Odontopediatria (AGOPED) conducted in September 2012 with the title Fluoride Dentifrices in Primary Childhood: Risks and Benefits. The conclusions of the Symposium were as follows: based on the best available scientific evidence about strategies to control dental caries, it is recommended that a fluoride dentifrice of at least $1100 \mathrm{ppm}$ of fluoride be used two times a day as an adjuvant for tooth cleaning by all children; during the phase in which children are not able to self-care, the use of fluoride dentifrice is a parents' responsibility warranting greater safety about dental fluorosis; it is also recommended that only a small amount of dentifrice (pea size) should be used for children under 2 years of age.
\end{abstract}

\section{Resumo}

Este Consenso reporta as conclusões advindas do Simpósio promovido pela Associação Gaúcha de Odontopediatria (AGOPED) realizado em setembro de 2012 intitulado Dentifrícios Fluoretados na Primeira Infância: Riscos e Benefícios. Como conclusões do Simpósio foram traçadas as seguintes recomendações: com base na melhor evidência científica disponível sobre estratégias para o controle de cárie dentária, se recomenda que um creme dental fluoretado de no mínimo 1100 ppm de flúor seja utilizado 2x/dia como coadjuvante da limpeza dos dentes de todas as crianças; enquanto a criança não tiver condições de se autocuidar, o uso de dentifrício fluoretado é de responsabildade dos pais ou cuidadores, garantindo assim maior segurança quanto à fluorose dentária; também se recomenda que seja usada apenas uma lambuzadela ("grão de arroz cru") de dentifrício fluoretado quando da limpeza dos dentes de crianças menores de 2 anos de idade.
${ }^{1}$ Professor Adjunto do Departamento de Odontologia Social e Preventiva da FOUFRGS. Diretor do Centro de Pesquisa em Odontologia Social da UFRGS.

${ }^{2}$ Professor Titular de Periodontia da FO-UFRGS

${ }^{3}$ Professor adjunto de Odontopediatria daFO-UFRGS

Correspondência: Fernando Borba de Araujo

Endereço: Rua Ramiro Barcelos 2492, Porto Alegre-RS, Brasil 90035-003 E-mail: fernando.araujo@ufrgs.br

A Associação Gaúcha de Odontopediatria (AGOPED), entidade que tem por finalidade, entre outras, promover o intercâmbio cultural, técnico e científico com entidades congêneres, pondo em prática medidas concretas para atingir seus objetivos, realizou nos dias 09 e 10 de setembro de 2012, um Simpósio intitulado "Dentifrícios Fluoretados na Primeira Infância: Riscos e Benefícios".

O objetivo deste Simpósio foi discutir com base na melhor evidência científica disponível os riscos e benfícios da utilização dos dentifrícios fluoretados na primeira infância. Sob a coordenação do Prof. Fernando Borba de Araujo, presidente da AGOPED, participaram desta atividade profissionais cirurgiões dentistas, odontopediatras e médicos pediatras (representando a Sociedade Brasileira de Pediatria), que durante 2 dias expuseram o seu entendimento sobre o assunto em seus mais diversos segmentos. São eles:

- SIMPOSIASTA 1: Prof. Jaime A. Cury (FOP.UNICAMP) "Riscos do uso do dentifrício fluoretado na 1a infância"

- SIMPOSIASTA 2: Profa. Lívia M. Tenuta (FOP.UNICAMP) "Benefícios do uso do dentifrício fluoretado na prevenção e controle de cárie na 1a infância"

- SIMPOSIASTA 3: Profa. Cecília C. Ribeiro (FO.UFMA) "Indicações clínicas para o uso do dentifrício de baixa concentração de flúor"

- SIMPOSIASTA 4: Profa. Simone T. Moyses (FO.PUC.PR) "Recomendações do Ministério da Saúde para o uso de dentifrícios fluoretados"

- SIMPOSIASTA 5: Prof. Danilo Blank (Faculdade de Medicina da UFRGS) "Entendimento dos médicos pediatras na recomendação de cremes dentais na 1a infância"

Na condição de ativadores deste Simpósio, participaram os Professores Cassiano K. Rosing e Fernando Neves Hugo, ambos da Faculdade de Odontologia da UFRGS, e a profa. Lina Zardo, representando as Sociedades Brasileira e Gaúcha de Pediatria. 
Após a apresentação dos trabalhos por parte dos simposiastas, o tema foi amplamente discutido pelos componentes da mesa com uma platéia extremamente numerosa e participativa. Ao final, foi redigido um documento com as seguintes conclusões:

1. Com base na melhor evidência científica disponível sobre estratégias para o controle de cárie dentária, se recomenda que um creme dental fluoretado de no mínimo 1100 ppm de flúor seja utilizado $2 x /$ dia como coadjuvante da limpeza dos dentes de todas as crianças;

2. Enquanto a criança não tiver condições de se autocuidar, o uso de dentifrício fluoretado é de responsabildade dos pais ou cuidadores, garantindo assim maior segurança quanto à fluorose dentária;

3. Também se recomenda que seja usada apenas uma lambuzadela ("grão de arroz cru") de dentifrício fluoretado quando da limpeza dos dentes de crianças menores de 2 anos de idade.

A AGOPED advoga a continuidade do processo de construção do conhecimento sobre o uso do dentifrício fluoretado a partir da primeira infância, com relação à efetividade e à segurança, valendo-se de ensaios clínicos randomizados, preferencialmente de base populacional.

Rev. Fac. Odontol. Porto Alegre, v. 53, n. 3, p. 41-42, set./dez., 2012. 